\title{
Boundary Crossing and the Construction of Cinematic Genre
}

\author{
By Steffen Hantke \\ Fall 2004 Issue of KINEMA \\ BOUNDARY CROSSING AND THE CONSTRUCTION OF CINEMATIC GENRE: FILM
NOIR AS "DEFERRED ACTION"
}

The Frame-Up: Theoretical Considerations

In recent years, critical consensus in cinema studies has begun to coalesce around the idea that, in a sense, there never was such a thing as film noir. Thomas Elsaesser, for example, comes to this conclusion after examining what might be called one of the foundational myths of film noir, the "connection between German Expressionist cinema and American film noir" (Elsaesser: 420). (1) Ever since this story about noir's origins has solidified into one of the "commonplaces of film history," Elsaesser argues, it has become difficult to see film noir for what it really is, "an imaginary entity whose meaning resides in a set of shifting signifiers" (Elsaesser: 420). Following a critical rather than a cinematic tradition, he traces the consolidation of the genre's identity back to the intervention of German exiles like Siegfried Kracauer and Lotte Eisner, whose work, respectively, in From Caligari to Hitler (1947) and The Haunted Screen (1969) established the foundations for the ways in which later generations of critics were to write the genealogy of noir cinematography. Elsaesser looks at Nino Frank and Raymond Borde and Etienne Chaumeton in the same light, wondering what role they played not in the discovery or classification of film noir, but in its invention or construction (Elsaesser: 422). Elsaesser concludes:

film noir has no essence, [...] its most stable characteristic is its 'absent-centredness', its displacements, its over-determinedness, whose ghostly existence as too many discourses, instead of canceling each other out, merely seems to amplify the term's resonance and suggestiveness. Most noticeable is the term's historical imaginary as deferred action (Nachtraeglichkeit). (Elsaesser: 423)

James Naremore follows Elsaesser's lead in pursuing this constructionist approach. Film noir, he writes, "belongs to the history of ideas as much as to the history of cinema; in other words, it has less to do with a group of artifacts than with a discourse" (Naremore, 11). To the degree that it is "a loose, evolving system of arguments and readings that helps to shape commercial strategies and aesthetic ideologies" (11), it has not only "become useful to the movie industry" (38), but also to academics and film historians. From Elsaesser's and Naremore's comments, film noir emerges as a commodity that is simultaneously material (books, video, DVD) and immaterial (the abstract idea of noir, invested in a variety of products as a marketable essence). Both commodities are produced as much by the studios, with their directors and producers, as by critics and reviewers, who are invested in the term as the coinage of professional and cultural capital.

Naremore also points out that, since noir is "a concept that was generated ex post facto," it can easily be transformed into "a dream image of bygone glamour" (39). This transfer of an ideological construct from critical discourse into "a worldwide mass memory" entails a process of fetishization, which, in turn, "represses as much history as it recalls, usually in the service of cinephilia and commodification" (Naremore 39). This fetishizing seems most starkly visible to critics outside of the US, critics like Marc Vernet for whom film noir is deeply implicated in the ways American culture circulates through global markets in the years after WWII. "Film noir," Vernet writes, "is a collector's idea that, for the moment, can only be found in books," endorsed by "those who wanted to love the American cinema even in its middling production" (26).

What I find remarkable about the constructionist argument, as Elsaesser, Naremore, and Vernet formulate it, is not that it is provocative or original, but that it aligns itself with certain tendencies within film noir itself that appear to be equally concerned with creating a vantage point from which a critical assessment of the noir universe can be performed. Intuitively, most of us would agree that these tendencies are so prevalent in neo noir that they virtually define it. But what I want to argue here is that neo noir has no exclusive claim on this constructionist approach. It appears that film noir, even in its classic cycle between the 1940s and the late 1950s, has always insisted that attaining a panoramic view of the noir universe itself is a crucial way of launching a critique about it. This persistence is perhaps less surprising considering that the world of 
film noir is conventionally described as bleak and claustrophobic. Given these characteristics, the idea that the inhabitants would want or plan to escape from this universe, with whatever results, seems like one of its obvious inbuilt features. To this end, film noir mobilizes an inventory of narrative strategies, of recurring themes, and of spatial tropes, which all address the diegetic totality of the noir universe and attempt to map out, synchronically speaking, a space "outside" or, diachronically speaking, a vantage point of "deferred action."

\section{"Well, this is where you came in . . .": Voiceover and Flashback}

The combination of flashback and voiceover has long been a staple of classic film noir, from Walter Neff dictating his confession to his boss Barton Keyes in Billy Wilder's Double Indemnity, to Jeff Bailey telling the story of his criminal life to his girlfriend Ann in Jacques Tourneur's Out of the Past. Most noir voiceovers borrow their laconic, cynical tone from the hard-boiled detective novel, from its carefully chiseled taciturnity and throwaway lyricism. So central has the device remained to the genre that neo noir is still experimenting with its possibilities. The omission of the voiceover from the director's cut of Ridley Scott's Blade Runner, for example, caused heated discussions among fans many years after the film's original release. (2) Most of the controversy revolved around the question whether Blade Runner, as a result of this alteration, was more or less noir now than in the theatrical release version. That ineffable quality of noir, its mood or flavor, seemed to hinge on the presence or absence of Harrison Ford's voice more than on any other trait of the film. (3)

Billy Wilder's two noir classics Double Indemnity and Sunset Boulevard mark the shift, in the work of a single director, from a more conventional use of voiceover, dictated primarily by narrative expediency, to its sly subversion. The combination of flashback and voiceover in Sunset Boulevard is cleverly dissociated from the diegesis simply because the narrator is already dead at the moment he begins to speak from outside the frame. To some extent, the device still functions in the tradition of noir that wants to achieve a "retroactive psychologization and subjectivization of the narrative" (Steinbauer Groetsch 121, my translation), a "subjective over-determination, where objective parameters become difficult to distinguish" (Krutnik 47). It signals an existential determinism in which the outcome of events is already decided at the point when the open-endedness of the narrative process still suggests that options and alternatives are available to the characters, a narrative looping that "enhance[s] the aura of doom" as the narrator "takes a perverse pleasure in relating the events leading up to his current crisis" (Porfirio 88). The voiceover in Sunset Boulevard articulates this determinism in the most dramatic way; after all, when you're dead, you're dead - the story couldn't be more over. But Wilder takes the device to its logical extremes, pushing it toward absurdity. It is a small but crucial step from Walter Neff's confession on the verge of death in Double Indemnity to Joe Gillis' story told from the other side of the great divide. Gillis speaks from an impossible position, violating the rules of narrative verisimilitude. The God-like detachment of the classic noir voiceover, spoken by a narrator who has seen everything and is surprised by nothing, is exposed as a contrivance by Wilder in the act of relocating the narrator to a position that, literally, hovers above the narrative universe.

The way Wilder shoots Gillis as the narrator of the voiceover is tongue in cheek as well. As his body is floating in the water of the pool "he always wanted," Gillis has not quite ascended toward celestial serenity but remains stuck in the somewhat denser element down below. Wilder's camera, positioned in a low-angle shot at the bottom of the pool might suggest elevation, but the witnesses are all above Gillis, framed on the margins of the same shot as blurry outlines above the water line. They are the ones who will eventually pass judgment on him and the circumstances of his death; and as the final scene of the film suggests, his existence and suffering at the hands of Norma Desmond will be obliterated by his killer's spectacular "comeback" from the dead. The swimming-pool shot, as well as the voiceover, are rife with irony and double entendre, both visually and verbally.

This irony comes between the voiceover and the visual diegesis of the film. Instead of fusing the two levels of signification as most other directors do, and as he himself has still done in Double Indemnity, Wilder opens up a space between them, making his audience conscious of their interaction. As long as both levels are fused and work in tight functional support of each other these questions seldom arise. Functional alignment of image and voice might suffice to suggest such seemingly self-evident connection. Like most noir narrators, Gillis and Neff are shown in the act of narration itself. The frame they occupy is, compared to the hefty embedded narrative within, rather slim, so that, at times, it is easy to forget that we are inside a frame 
at all. Wilder returns us to Neff in brief reminders of the frame narrative, but Gillis only returns dead at the very end of the film. Viewers are invited to contemplate the relationship of the two levels - frame and framed narrative - toward each other. Despite their use of the flashback/voiceover combination, Wilder's films are more self-conscious in this regard than more formulaic noir. By showing textual production, they thematize noir, not as self-evident style or as setting or self-contained universe, but as something fabricated or produced, under specific circumstances, by a specific author, and with a specific set of authorial intentions and effects.

In the most crucial sense, it is a rhetorical production, conceiving of noir primarily as a narrative text. It is the product of a human voice, of spoken words. Though this places the self-reflexive metaphor into a tradition that looks backward to oral narrative, Wilder manages to insert details that orient the metaphor forward. Just as Gillis' omniscience in the voiceover is ironically fractured by the radical break with verisimilitude, Neff speaks to Keyes from a distance as well. Instead of making his confession directly to him in person, he lets technology intervene between him and "his conscience" by speaking into a dictaphone. Because the recording device comes between the two men, the act of textual production itself is seen, at least in part, as a technological process from which the actual speaker, disembodied, is absent. If it were not for Keyes appearing at the office as Neff reaches the climactic end of his confession, the recording of Neff's voice would be the only thing left of him. He would be reduced to a trace, open to interpretation but also fixed and unchangeable. Like cinema itself, his presence could only be produced by means of an advanced recording technology.

As much as directors of classic noir like Wilder succeed in manipulating the device of the voiceover/ flashback to comment on the production of noir itself, the device itself tends to have an inherent limitation. Even the most creative versions of the device, whenever they successfully pry the voiceover loose from the visual diegesis, need to situate the narrator of the voiceover inside the narrative universe of noir. That is to say, the limit of how wide the gap of irony in the service of self-reflexivity can be opened up is established by the generic convention of the narrator being simultaneously, and perhaps somewhat paradoxically, above and inside the narrative universe. In Otto Preminger's Laura, the narrator is the man who turns out to be the murderer. His function in the plot suggests that he operates outside the socially and morally sanctioned rules of the narrative universe, perhaps even thinking of himself as being above them altogether. The same goes for the Jeff Bailey character in Tourneur's Out of the Past, who narrates not the detective's but the criminal's point of view. Morally different as these characters might be, they still need to be ontologically rooted in the same universe, participating in the events they reflect on in their voiceover. ${ }^{4}$ ) Though ironic refractions are still possible, as Laura and Sunset Boulevard demonstrate, the self-reflexivity of the trope is limited. If voiceover narration represents the production of the noir text, and if it always originates from within this text, then noir, in a manner of speaking, produces itself. The world of noir is a self-contained universe that, properly speaking, has no outside.

It would be possible to imagine a space outside this hermetic universe if frame and embedded narrative were to diverge permanently, if the voiceover were to emanate from a position undeniably outside the world of noir. But generic conventions demand that frame and embedded story must mesh sooner or later, most likely to guarantee that the thematic function of the device remain intact. Barton Keyes appears in person to witness the end of Neff's testimony in Double Indemnity; the resolution of the moral problem of their friendship whether Keyes will let Neff get away with murder--begins in the embedded narrative but is resolved in the frame. Along the same lines, Sunset Boulevard justifies the existence of the frame narrative by raising the question how this man ended up in this pool; with Gillis' murder, the embedded narrative is fused with the frame and the question is answered. In both cases, just as in the majority of all noir voiceover, the fusion of both narrative trajectories produces a coherent, seamless universe.

A closer look at Sunset Boulevard reveals of course that the film does not end with Gillis' body floating in the pool, but with Norma Desmond's mad yet triumphant descent down the staircase and into the arms, and minds, of her loving audience. Her famous lines - "There's nothing else, just us, and the cameras, and those wonderful people in the dark" - illustrate the fact that her (skewed) perspective dominates the narrative at this point, even when it is still supposedly Gillis' narration we are experiencing. This could be a final loving concession of Gillis' to Norma, or rather, a final concession to her superior power. In this closing scene, we also see Hedda Hopper phoning the events in to her editor, her narration substituting for Gillis', which only 
comes back briefly with his final concession to Norma's triumph. All this could be read as signals that, as we move from the embedded narrative into the frame, we also move from an intimate, personal narrative to a public story, and thus from the cozy conventions of $19^{\text {th }}$ century realism to a new $20^{\text {th }}$ century aesthetics of spectacle. The new aesthetics substitutes the faux familiarity of celebrity culture for the genuine intimacy of interpersonal relations. This means that the journalists' cameras and microphones in the closing scene of Sunset Boulevard fulfill the same function as Walter Neff's dictaphone in Double Indemnity; they are markers of a technology that produces the text of noir.

Without the possibility to encode an outside agent into the noir text as a convincing trope of textual production, the noir universe, on some level, is always an encapsulated totality. There might be internal rifts, but the boundary around the world, its perimeter, is inviolable. On the most pragmatic level, this is inevitable and useful because the genre depends, to a considerable degree, on the willing suspension of disbelief. If the audience is supposed to respond to the noir characters' moral conflicts and inner lives, then certain limits must be imposed upon how far metatextual self-examination can be allowed to proceed. No doubt, neo noir has produced a variety of texts, both in film and literature, which go all the way in overstepping the limits of verisimilitude and widening the metatextual boundaries of the genre. Paul Auster's New York Trilogy, Haruki Murakami's Hardboiled Wonderland and the End of the World, Kim Newman's The Night Mayor, Scott McGehee's and David Siegel's Suture, or even Robert Zemeckis' Who Framed Roger Rabbit? are prime examples of neo noir that poses radical questions about the production of noir as a text, a genre, and as a kind of cultural practice. But even these films still seem to be looking for an Archimedean fulcrum from which the noir universe can be levered, a position that, by its very definition, would have to be outside that universe.

\section{Blowing Town: Geographic and Architectural Space}

Robert Porfirio has pointed out that a basic optimism in American culture needed to undergo a number of sobering experiences before "existentialism [could] gain a foothold in post-war America [...]: the Depression; the rise of totalitarianism; the fear of Communism; the loss of insular security; and, finally, the tarnishing of the idea of individual initiative with the growth of the technocratic state" (80). These experiences affect a change specifically in the way landscape functions within American mythologies of unlimited mobility. "The American has not yet assimilated psychologically the disappearance of his own geographical frontier, his spiritual horizon is still the limitless play of human possibilities, and as yet he has not lived through the crucial experience of human finitude" (Barrett qtd. in Porfirio 80).

The metaphor of the "spiritual horizon," to describe the cognitive breakthrough to an "authentic life," feeds right into noir claustrophobia. The horizon in film noir, visually obstructed by expressionistic angles and shadows in the mise en scene, is always a sharp demarcation of the character's freedom, or lack thereof. Unlike the perpetual incitement to keep moving westward, the horizon in film noir is either difficult to make out, and if it is visible, it is often set, unmoving, unyielding. Characters who attempt to escape either die or are returned to where they started. Each failed attempt at escape only re-enforces the prevailing mood of claustrophobia.

Given the spatial coding of social and ideological mobility, it is hardly surprising that noir's favorite, and in many ways most obvious, metaphor for mapping itself as textual product is spatial. The metaphor sounds oxymoronic, and can best be summarized like this: inside the narrative universe, there is a topographic location that is not just marginal but promises to be genuinely outside. Often, the paradox is resolved when characters realize that the space exists but is unattainable, or that it exists as a utopian myth, detached from empirical reality. In this regard, this "outside on the inside" functions as what I would call a "spatial other," an object of retrogressive desire (nostalgia) or progressive desire (utopia), always defined by its absence, deferral, or unattainability. For the most part, it is associated with proximity to origins, beginnings, and hence authenticity, in sharp contrast to the industrial city, the "archetype of the artificial environment" (Bukatman 105). Plenty of characters are trying, almost always in vain, to blow town and make a run for it, from Neff's plea to Keyes to give him a chance to reach the Mexican border in Double Indemnity, to Joe Gillis' listless contemplation of leaving Hollywood and returning to his native Ohio, to Sterling Hayden's bank robber foiled at the last minute in his escape in Kubrick's The Killing. Hayden's physical solidity and stoicism lends an air of tragedy to these failed escapes, and so it is hardly surprising to see him in the same role, "a bluegrass boy bushwhacked by the big city" in John Huston's The Asphalt Jungle (Muller 146). Here 
he plays a character named Dix Handley who has come to the city from rural Kentucky. After the big caper, he plans to return to the idyllic family farm that was lost "to the banks" during his childhood and "take a bath in the creek and wash this city dirt off." The reference to the Great Depression establishes the first ambiguity about this spatial other, which might be located in a mythical elsewhere, but is still determined by socioeconomic forces rooted in the urban centers of the US. Nonetheless, Handley construes this space as a utopian other to the city. While his life in the "asphalt jungle" displays modernity's social pathology - random acquaintances, unstable social and gender identities, the loss of control as a result of encroaching middle or old age, alienation, and violence - the Kentucky farm represents pre-industrial agrarian values, such as family, childhood or youth, rootedness and tradition, and stable identity.

In its closing scenes, The Asphalt Jungle makes good on its promise and takes the character, as well as the audience, out of the noir city and back to the rural utopia. Handley has been seriously injured during the heist and is slowly bleeding to death, not unlike Walter Neff in Double Indemnity, as he approaches the space that promises personal rehabilitation. But the plan fails, and nostalgia is revealed as fiction. As he gets out of the car, his injuries catch up with him, and he dies. The fatal reach of the noir city extends to this space, which is construed as an Other but revealed as an extension, a margin belonging to essentially the same space. The noir universe is revealed as homogeneous after all; there is no outside.

What is crucial about this spatial construction in Asphalt Jungle is not the existence of this spatial Other, but its function as a utopian ideal motivating the characters individually and supplying a social counterbalance to noir claustrophobia. That the audience shares this desire to escape the clutches of the noir universe becomes obvious through the emotional investment in Dix Handley and his quest. The emotional integrity of the story is staked on this investment. But even when there is no specific character to whom this desire for a spatial Other is attached, audiences still respond to the homogeneity of the noir universe with this same desire. This free-floating desire for a "spatial other" drives the closing sequence of David Fincher's neo noir film Seven. Except for the final fifteen minutes of the film, Seven takes place entirely within a noir cityscape. Shot in muted blue and gray tones, the city is drenched in incessant rain, visual shorthand for the violence, corruption, and alienation to which all characters in the film are exposed. After a long search, the two detective figures apprehend the killer, only to discover that he has left a final clue in a location to which he promises to lead them personally. As the three make their way toward this unknown destination, Fincher's camera tracks their progress with overhead shots from the helicopter that provides backup. Gradually, the urban setting dwindles away, and a strangely incongruous countryside takes its place. While the nameless city looked like New York, or any large city on the East Coast, the countryside around it, within an hour's driving distance, looks like the desert to the east of the greater Los Angeles area. By merging these two locations, Fincher might be aiming for a generic amalgamation of typical noir locations, along the axis of Los Angeles in the West and New York in the East, with assorted mid-western cities in between. Read this way, the geographic inconsistency functions as a metatextual nod toward the noir tradition. The city is simply a noir icon, stripped of all geographic and cultural specificity. But the thematic integration of this abstract setting into the rest of Seven points in a different direction.

What the move to a desert location allows is a shift of the film's color spectrum from the cold, drab blue tones to gorgeous warm reds. The escape from the dystopian nightmare of the noir city is also accompanied by the first direct sunlight, as the clouds finally break and the early evening sun casts a warm and deeply nuanced light onto the scene. The change in weather and light fit perfectly with the promise of an imminent resolution to the plot's violence. We are close to the end, about to escape from a world of violence into a world of justice, a world of entropic serial recursiveness into a world of liberating narrative closure. The overhead shots of the car moving through this clean, well-delineated landscape further suggest clarity - we are no longer submerged in an indifferent, even hostile universe but hovering above it. The overhead shots from the moving helicopter grant us perfect vision, a kind of divine establishing shot, and free-floating mobility.

Like Dix Handley's nostalgia for the Bluegrass Country of his childhood, the desert location around the noir city in Seven is clearly marked as utopian, a counter-space that allows escape from the strictures of the noir universe. From the detachment of this outside position, the noir city might be contemplated with calm objectivity, properly assessed, and thus controlled and made habitable. But like Huston, Fincher denies his characters and his audience this moment of relief. Like The Asphalt Jungle, Seven reveals this space as an extension of the noir city, inside the periphery of the same world. The killer has set the stage for a scene in 
which his own agenda will triumph over that of the detectives, implicating one of them, Mills (Brad Pitt) in his violent scheme by making him an accessory to murder. By the same token, he forces the other detective, Somerset (Morgan Freeman) into a moral conundrum that has him resume his duties in the city rather than retire to a house in the country as he had originally planned. While Mills is destroyed by the city, Somerset is pulled back in. All of this takes place in a space that, at first glance, appears as an alternative to this urban dystopia. For the audience, as for the characters, the film ends with the recognition of the inescapable grasp of the noir universe. There is no escape, because there is no outside to escape to. Spatially, The Asphalt Jungle and Seven close the gap between noir and its other, just as the use of voiceover in Double Indemnity and Sunset Boulevard deny the audience any opportunity to place themselves outside the noir universe and contemplate its production.

\section{Wilder At Heart: Conclusion}

J.P. Telotte has pointed out that, even before neo noir self-consciously begins to explore the constructedness and artificiality of its narrative worlds, classic noir already marks "a stress point in American film narrative" because films of the classic cycle, in a broad sense, "increasingly engage that notion of a constructed world" (178). In its use of documentary techniques as a stylistic counterpoint to German Expressionist interiority and subjectivity, classic film noir "sought to accommodate or function within an increasingly elusive, if not quite illusive, "real," even as it often sought, through a variety of strategies, to attest to its own more realistic vantage on our world" (178). What Telotte is addressing is noir's ambivalence between what one might call two incompatible rhetorical modes - the fantasmagoria of expressionist style on the one hand, and the cool-headed empiricism of the documentary tradition on the other - an ambivalence that speaks to the problem of reconciling verisimilitude with the predictability and formality of cinematic genres.

The strategies I have outlined in classic noir texts differ from those that underlie Telotte's argument. What is at stake in Wilder's use of voiceover and in Huston's or Fincher's use of the spatial other is not the anxiety that the text could disintegrate under the burdens of having to capture empirical reality; that, in other words, it could prove incapable of fulfilling its dramatic, narrative, and thematic functions. The opposite is the case. The cause of anxiety is that it could fulfill its functions too well. The totality of the discursive space of the genre is the cause of anxiety. Its seamlessness and claustrophobic inescapability preclude its ability to step outside of itself, critically evaluate itself, and reflect upon its own status as a cultural construct. Inside the discursive space, there are niches, lacunae, opportunities for exploring irony, but the space itself in which this exploration takes place remains exempt from challenge; after all, there is no space to challenge it from. One wonders how much directors like Billy Wilder, whose scripts are masterpieces of dramatic irony, were bothered by being unable to articulate something like "generic irony" when they were working within the constraints of film noir.

Not yet fully sanctified by a position of "deferred action," the strategies used by directors like Wilder only begin to emerge as a dominant feature of film noir after the classic cycle. While most of us would overlook them in classic noir, we would easily recognize them in neo noir because here they are reabsorbed into a high level of self-reflexiveness and appear prominently in the textual foreground. Carl Reiner's Dead Men Don't Wear Plaid, for example, stages a breakdown of the hardboiled voiceover in a scene in which a female character answers out loud to her partner's voiceover, which by the rules of ontology, should be inaudible to her. Similarly, the answer to the question Who Framed Roger Rabbit? is so obviously "Well, Robert Zemeckis, of course!" that the double entendre never disrupts the film's diegesis. In Alex Proyas' Dark City, viewers are privy to the construction of an urban environment, the film's eponymous Dark City, straight out of film noir, which serves, literally, as a textual device for the construction and co-optation of individual and collective subjectivities. ${ }^{(5)}$ To the degree that these neo noir texts raise the strategies - the ones I have discussed in the context of classic noir - above the threshold of conscious perception for the audience, they are involved in the actualization, continuation, or finalization of the same problems noir has been struggling with all along.

The continuity between the classic cycle and neo noir is difficult to see, however. The same strategies are already present in classic film noir, but they are deployed in subtle, understated forms. They are not meant to disrupt the diegetic surface. They always stop short of pushing the films into an overt self-reflexivity that would have been likely to alienate a mainstream audience. But as Telotte has pointed out, film noir has never, at no point in its historical development, been self-evident. Because of its hybrid genealogy, it has 
always been troubled by the suspicion that the machinery that constructed and launched it might be showing all too plainly. According to Elsaesser's and Naremore's argument, critical discourse has done its part, from the position of deferred action, in smoothing over the rifts and closing the gaps that the texts themselves have been trying to open up. The spirit of critical self-examination did not enter film noir belatedly, the exclusive property of neo noir's return as nostalgia and pastiche. It has been there all along. Speaking from a position of deferred action myself, I would argue that it is one of the crucial ingredients that contribute to film noir's modernity and enduring relevance.

\section{Notes}

1. Quotes from Elsaesser are from his book Weimar Cinema and After (2000), though this specific argument was published originally in "A German Ancestry to Film Noir? Film History and its Imaginary," Iris 21 (Spring 1996).

2. See, for example, the viewers' reviews listed on the cult-film.com web site: (http://www.cult-film.com/scifi_and_fantasy/blade_runner_\%5Bdirectors_cut\%5D/).

3. By contrast, science fiction, especially when it aims for the epic tone of space opera, allows for the omniscient narrator to be outside the narrative universe. The most prominent example is the much-parodied opening of Lucas' Star Wars films with its written exposition scrolling down the screen. The device, clunky and perhaps condescending toward the audience, serves primarily as a signifier of postmodern nostalgia couched in terms of popular genre rather than actual history.

4. See Steinbauer-Groetsch's remarks on the various functions of the voiceover-flashback combination: 10732 .

5. Other examples are Josef Rusniak's The Thirteenth Floor (1999), David Cronenberg's eXistenZ (1999), and the Wachowskis' The Matrix (1999). Preceding these films by a year, Peter Weir's The Truman Show (1998) and Gary Ross' Pleasantville (1998) initiated the theme of this cycle. Though the emancipatory narratives in the latter two films resemble those of the neo-noir films I have listed, they do not deploy noir

imagery, perhaps because they are primarily interested in a critique of the medium of television (instead of cinema) and only secondarily in a critique of popular genres (in these two cases, respectively, reality TV and the family sitcom).

\section{References}

\section{Works Cited}

Bukatman, Scott. Matters of Gravity: Special Effects and Supermen in the 20 ${ }^{\text {th }}$ Century. Durham/London: Duke University Press, 2003.

Elsaesser, Thomas. Weimar Cinema and After: Germany's Historical Imaginary. London/New York: Routledge, 2000.

Krutnik, Frank. In a Lonely Street: Film Noir, Genre, Masculinity. London/New York: Routledge, 1991.

Muller, Eddie. Dark City: The Lost World of Film Noir. New York: St. Martins Griffin, 1998.

Naremore, James. More Than Night: Film Noir in its Contexts. Berkeley: California UP, 1998.

Porfirio, Robert. "No Way Out: Existential Motifs in the Film Noir." Film Noir Reader. Eds. Alain Silver and James Ursini. New York: Limelight Editions, 1996. 77-95.

Sikov, Ed. Commentary Track. DVD. Sunset Boulevard. Dir. Billy Wilder. Perf. Gloria Swanson and William Holden. Paramount, 1950. DVD. Paramount Home Video, 2002.

Steinbauer-Groetsch, Barbara. Die Lange Nacht der Schatten: Film Noir und Filmexil. Berlin: Bertz, 2000.

Telotte, J.P. "Lost Memory and New Noir." Paradoxa: Studies in World Literary Genres 16 (2001): 177-89. 
Vernet, Marc. "Film Noir on the Edge of Doom." Shades of Noir: A Reader. Ed. Joan Copjec. London/New York: Verso, 1993. 1-33.

\section{Author Information}

Steffen HANTKE is Assistant Professor in the Cultural Studies program of Sogang university's English Department in Seoul. He serves as an area chair for horror at the Southwest/Texas Popular Culture and American Culture Association and on the editorial board of Paradoxa. He has written on American literature and film in Literature/Film Quarterly, Journal of Popular Culture, Post Script, and elsewhere. 